Copyright (C) 2018 by Academic Publishing House Researcher

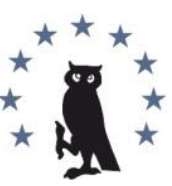

Published in the Russian Federation

European Researcher. Series A

Has been issued since 2010.

ISSN 2219-8229

E-ISSN 2224-0136

2018, 9(2): 144-152

DOI: 10.13187/er.2018.2.144

www.erjournal.ru

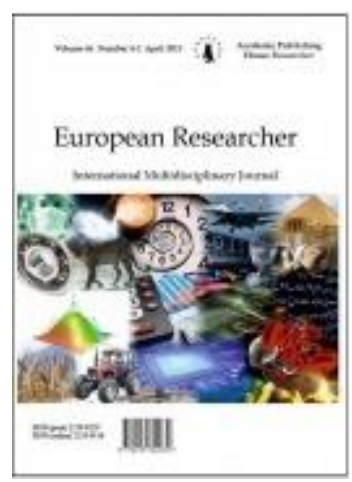

\title{
Scientific Connections in the Works of V.I. Guerrier (1837-1919). Analysis of References
}

\author{
Konstantin A. Minenko a, * \\ ${ }^{a}$ Saint-Petersburg State University, Institute of Philosophy, Russian Federation
}

\begin{abstract}
In this paper analysis of references will be used to study scientific connections. We will analyze a work by a famous Russian historian Vladimir Ivanovich Guerrier named "Western monkhood and papacy", part of which is dedicated to the life and works of Bernard of Clairvaux. Through the analysis of references in this work we will learn, which scientists have had the most impact on Guerrier while he was writing "Western monkhood and papacy". Also, we will research the writings of these authors, their methodology and scientific background. This will help us to show, how the tradition of perceiving human history as a biography of great men influenced Russian historiographical tradition.
\end{abstract}

Keywords: history of science, Guerrier, medieval studies, references, methodology.

\section{1. Введение}

История науки на сегодняшний день остается одним из самых перспективных направлений для исследования. К этой области можно применять самую разнообразную методологию, и в данной статье мы предпримем попытку обосновать полезность использования метода анализа справочного аппарата.

Приоритетом для нашего исследования будет контекстуальный анализ именно справочного аппарата, а не основного текста научного сочинения. В центре внимания данной статьи будет работа Владимира Ивановича Герье (1837-1919) «Западное монашество и папство», выпущенная в 1913 г. Герье - одна из ключевых фигур в российской историографии XIX, он не только оставил после себя множество научных сочинений, но и воспитал целое поколение учеников, среди которых были такие выдающиеся российские историки, как М. С. Корелин (1855-1899), П. Г. Виноградов (1854-1925), Н. И. Кареев (18501931), Р. Ю. Виппер (1859-1954) и С. А. Котляревский (1873-1939).

Как мы продемонстрируем в данной статье, на труды Герье определенное влияние оказали представители различных течений в европейской историографии. Учитывая важность фигуры Герье для российской исторической науки, мы полагаем, что было бы полезно проследить, какие иностранные авторы оказали на него наибольшее влияние.

\section{2. Материалы и методы}

Для того чтобы решить данную задачу, мы воспользуемся методом анализа справочного аппарата. Сноски, на первый взгляд кажущиеся лишь формальным элементом исследования,

\footnotetext{
${ }^{*}$ Corresponding author

E-mail addresses: koxminenko@gmail.com (K.A. Minenko)
} 
могут быть источником сведений об авторе конкретной работы. Через ссылки мы можем увидеть, какие исследования ученый использовал больше всего, какие из них оказали на него наибольшее влияние. Что особенно важно, мы можем видеть и то, как автор оценивает те работы, на которые он ссылается. Таким образом, анализ справочного аппарата может послужить хорошим инструментом для своеобразной реконструкции процесса написания научного сочинения. К ссылкам и сноскам нами будут применены принципы, которые лежат в основе изучения маргиналий и глосс в средневековых рукописях.

Книга Герье, справочный анализ которой мы будем анализировать, называется «Западное монашество и папство» и вышла в 1913 году. В предисловии Герье называет книгу продолжением другой своей работы под названием «Блаженный Августин. Зодчие и подвижники Божьего царства», которая, в свою очередь, была опубликована в 1910 году. По мнению Герье, в основе средневековой культуры Западной Европы лежит противоречие, заключающееся в том, что Римская церковь, пытаясь построить «Царство Божие» на земле, все больше отдалялось от самого этого идеала (Герье, 1913). Задачей своего исследования Герье называет изображение этого противоречия «в лице и в деятельности двух умственно и нравственно выдающихся подвижников Божьего царства - монаха св. Бернарда из французского монастыря Клерво - величайшего представителя аскетизма феодальной эпохи - и папы Иннокентия III, наиболее успешно осуществлявшего идеал теократии, то есть божеского управления на земле» (Герье, 1913). Учитывая, что данная статья не претендует на всеобъемлющий анализ наследия Герье, мы рассмотрим только ту часть его работы, которая посвящена Бернарду Клервоскому.

\section{3. Обсуждение}

Прежде всего, стоит уделить некоторое внимание восприятию истории самого Герье. Он учился в Московском университете в то время, когда там преподавали Грановский и Кудрявцев. Тем не менее, как отмечает Вайнштейн, назвать Герье учеником Грановского не представляется возможным (Вайнштейн, 1940). Герье был противником позитивизма в исторической науке, в частности, он критиковал «Историю цивилизации» Бокля. Наибольшее внимание в своих работах Герье уделял месту личности в истории; большинство его работ строятся вокруг истории жизни конкретного человека.

Итак, перейдем к рассмотрению сочинения Герье. Феномен папства, как мы уже отмечали выше, особенно интересен Герье в связи с кажущимся антагонизмом католического аскетизма (то есть попытки уйти от мира) и стремления Римской церкви завладеть всем миром. По его мнению, «достаточно поименовать эти принципы, чтобы усмотреть их противоположность», но, вместе с тем, «достаточно самого беглого знакомства с историей папства, чтобы убедиться в их постоянном взаимодействии в данном случае» (Герье, 1913). Герье полагает, что именно стремление к аскетизму дало возможность католической церкви возвыситься в земном мире. В связи с этим, он замечает (Герье, 1913), что подобная тематика оказывается благодатной почвой для историков-полемистов, которые «на почве средневековой истории вели борьбу с принципами и притязаниями современного католицизма» (Герье, 1913). В качестве примера подобного исследования Герье называет работу бельгийского историка Франсуа Лорана (Francois Laurent, 1810-1887) под названием «Etudes sur l'histoire de l'humanite» («Исследование истории человечества»), к которой мы вернемся позже уже в ходе анализа справочного аппарата. Противоречие, которое Герье видит, как «господствующую черту средневековой истории» (Герье, 1913), восходит к одному ключевому историческому персонажу - Аврелию Августину. Именно его концепция града Небесного заложила основы отношения католической церкви к миру. Герье предлагает обратиться к своему сочинению, специально посвященному Августину, которое мы уже упоминали выше, а также вкратце его пересказывает в «Западном монашестве и папстве».

Однако перейдем непосредственно к той части книги, где речь идет о святом Бернарде. Она открывается строками, которые особенно важны для понимания того, как Герье видит историю: «Существенное содержание истории составляют идеи. Они дают направление творческой деятельности исторических лиц и управляют событиями. В последнее время историки стали обращать больше внимания, чем прежде, на интересы: интересы экономические и вызванные условиями, в которые поставлена хозяйственная жизнь 
народов; интересы социальные, вызванные потребностями отдельных слоев в народе; но такое изучение интересов не уменьшило значения идей. Напротив, мы постоянно видим, что самые интересы становятся под знамя какой-нибудь идеи, стараются воспользоваться господствующими идеями, чтобы восторжествовать в борьбе с противоположными интересами» (Герье, 1913). Принимая во внимание эту цитату, сложно не согласится с Вайнштейном, который в «Историографии средних веков» пишет: «во всех своих произведениях Герье стоит на крайне идеалистических позициях, подчеркивая «громадное влияние идей на судьбу народов и на ход цивилизации». История идей и является главной темой его исторических работ» (Вайнштейн, 1940).

Главной идеей средневековья Герье как раз полагает идею «Божьего царства», а главным ее представителем и носителем он называет Бернарда Клервоского. И если мы проследим, как на страницах своей книги Герье раскрывает этот тезис, то мы увидим, что лучше всего методологию Герье резюмирует он сам: «главными источниками историка всегда останутся произведения человеческого слова и главным предметом его изучения всегда останутся события, которые совершались внутри человека и которые поэтому доступны только психологическому анализу» («Русский Вестник», 1865, т. 60, стр. 55). Таким образом, единственным источником исследования для Герье становятся тексты святого Бернарда.

Это подтверждается количеством ссылок, которые Герье дает на сочинения Бернарда. Подавляющее большинство сносок в той части книги, главным героем которой является Бернард, - это ссылки на издание его трудов, выполненное католическим священником Жаком Полем Минем (Jacques Paul Migne, 1800-1875), напечатавшим колоссальную антологию сочинений Отцов Церкви (Patrologia Latina и Patrologia Graeca). В эту антологию были включены работы богословов и церковных писателей от II до XV века. Вся антология включает в себя 381 том и до сих пор сохраняет свою популярность в учебных заведениях в виду своей доступности. Очевидно, была эта антология доступна и Герье, который именно ее использовал для цитирования Бернарда.

Еще один источник цитат святого Бернарда в работе Герье - это сочинения французского священника, историка и теолога Эльфежа Вакандарда (Elphège Vacandard, 1849-1927). В частности, Герье ссылается на его работу под названием «Оратор Святой Бернард» («Saint Bernard orateur»), вышедшую в 1877 году. Работы Вакандарда о Бернарде Клервоском переведены на множество языков и являются классикой для данной тематики (Bredero Adriaan, 1996). Вакандард - католический историк, что, очевидно, накладывает отпечаток на его исследования. Он получил образование в семи, в 1882 году стал членом Академии наук, изящной словесности и искусств Руана (Arnold of Brescia, 1917) (L’Académie des Sciences, Belles-Lettres et Arts de Rouen), а в 1891 году он стал ее президентом (Arnold of Brescia, 1917). Несмотря на авторитет Вакандарда, современные историки критически рассматривают некоторые моменты его исследований (Arnold of Brescia, 1917).

Однако для нашего исследования важно то, что Герье использует сочинение Вакандарда только для цитирования Бернарда, а не обращается к тексту самого ученого. Возможно, это свидетельствует о том, что Герье не рассматривал работу Вакандарда как собственно исследование, а скорее, как изложение взглядов Бернарда, в котором можно было подчерпнуть некоторые его цитаты. Тем не менее, работы Вакандарда в первые десятилетия XX века были авторитетом для многих ученых, а потому неудивительно, что Герье был с ними знаком. Более того, он дает еще одну ссылку на Вакандарда:

Послание к рыцарям храма хотя и дышит воинским пылом, но оно составлено в тищи монашеской кельи; деятельность же проповедника и организатора крестового похода требовала продолжительного общения с миром 1). С. 76
1) О роли Бернарда в проповеди второго крестового похода и его отношении к этому делу см. Vacandard, «St. Bernard et la Seconde Croisade» (в «Revue des questions historiques», 1885, 398); он следует выводам Нейманна: D. h. Bernhard u. die Anfrange des 2 Kreuzzuges. 1882 . 
В данном случае, это ссылка, которая предоставляется для читателя, чтобы он мог подробнее ознакомиться с конкретной темой. То, что Герье ссылается на статью Вакандарда, означает, что он высоко оценивал ее. Еще один вывод, который мы можем сделать благодаря этой сноске - это то, что Герье был знаком и с немецкоязычной литературой по теме своего сочинения.

Отчетливым для нас предстает отношение Герье к еще одному труду, на который он ссылается - многотомному «Исследованию истории человечества» Франсуа Лорана. Выше мы уже упоминали о том, что Герье полагал сочинение Лорана полемическим, направленным против распространения клерикализма в Бельгии. Несмотря на недостатки, которые Герье отмечает в работе Лорана, он признает у автора «выдающуюся начитанность» (Герье, 1913) и серьезный характер его исследования. Вместе с тем, Герье в своем сочинении зачастую полемизирует с Лораном, не соглашаясь с его оценкой деятельности Бернарда Клервоского.

Для нашего исследования важно понять, почему именно Герье ссылается именно на работу Лорана. Для этого мы обратимся к фигуре самого Франсуа Лорана (Lameere, 1905). Высшее образование он получил в Государственном университете Лёвена (l'Universite d'Etat de Louvain), продолжил его в Льежском университете (l'Universite d'Etat de Liege). После Бельгийской революции 1830 года он работал в министерстве юстиции нового государства. C 1836 по 1882 год он преподавал право в гентском университете (l’Universite de Gand). Лоран стал автором фундаментальных работ: 33 тома «Принципов гражданского права» («Principes de droit civil»), представляющие из себя комментарий и исследование кодекса Наполеона, 18 томов «Исследования истории человечества» («Etudes sur l'histoire de l'humanite»). В своих трудах он уделял большое внимание отношениям церкви и государства, при этом, он не скрывал своего антиклерикализма.

Во многом за предвзятое отношение к церковным деятелям и Бернарду Клервоскому в частности, Герье и критикует работу Лорана. Мы можем видеть это на примере тех цитат, которые мы приводим здесь:

\begin{tabular}{|c|c|c|}
\hline $\begin{array}{l}\text { Отношение Бернарда к знанию и } \\
\text { науке заслуживает особенного } \\
\text { внимания. Его } \text { нередко } \\
\text { выставляют ненавистником } \\
\text { знания, и это не трудно сделать, } \\
\text { если приводить отрывочные } \\
\text { выражения его без связи с его } \\
\text { общей мыслью. Так, напр., Лоран } \\
\text { говорит о нем, что он «расточал } \\
\text { презрение к ученым и науке» 3). } \\
\text { Такой отзыв слишком узок и } \\
\text { пренебрежителен по отношению } \\
\text { к противнику или лицу другого } \\
\text { направления, т.-е. дает повод } \\
\text { именно к тому самому упреку, } \\
\text { который Лоран делает Бернарду. } \\
\text { С. } 66\end{array}$ & $\begin{array}{l}\text { 3) Laurent. } \\
\text { Etudes s. l'H. de } \\
\text { l'Hum., VIII, p. } \\
\text { 145. }\end{array}$ & $\begin{array}{l}\text { Цитата с указанной страницы: } \\
\text { Il est certain qu'il prodigue le mepris } \\
\text { aux savants et la science }\end{array}$ \\
\hline $\begin{array}{l}\text { Этой страницей Бернарда легко } \\
\text { воспользоваться для полемики } \\
\text { против средневекового } \\
\text { католичества или аскетизма. Так } \\
\text { поступил, между прочим, и } \\
\text { Лоран в своем почтенном при } \\
\text { всей своей тенденциозности } \\
\text { труде 1), выбрав и сопоставив из } \\
\text { трактата Бернарда все резкие } \\
\text { места (еnormites), в которых }\end{array}$ & $\begin{array}{lr}\text { 1) } & \text { Laurent. } \\
\text { Etudes } & \text { s. } \\
\text { l'Histoire } & \text { de } \\
\text { l'Humanite. } & \\
2 \text { ed., t. } & \text { VII, } \\
\text { p. 253. } & \end{array}$ & $\begin{array}{l}\text { На указанной странице не } \\
\text { представляется возможным найти } \\
\text { что-либо относящееся к тому, о чем } \\
\text { пишет Герье. } \\
\text { Тем не менее, на } 290 \text { странице } \\
\text { сочинения Лорана находим: } \\
\text { Les ordres militaires sont, aux yeux de } \\
\text { saint Bernard, la plus admirable des } \\
\text { institutions: «Les moines guerriers, }\end{array}$ \\
\hline
\end{tabular}




\begin{tabular}{|c|c|}
\hline 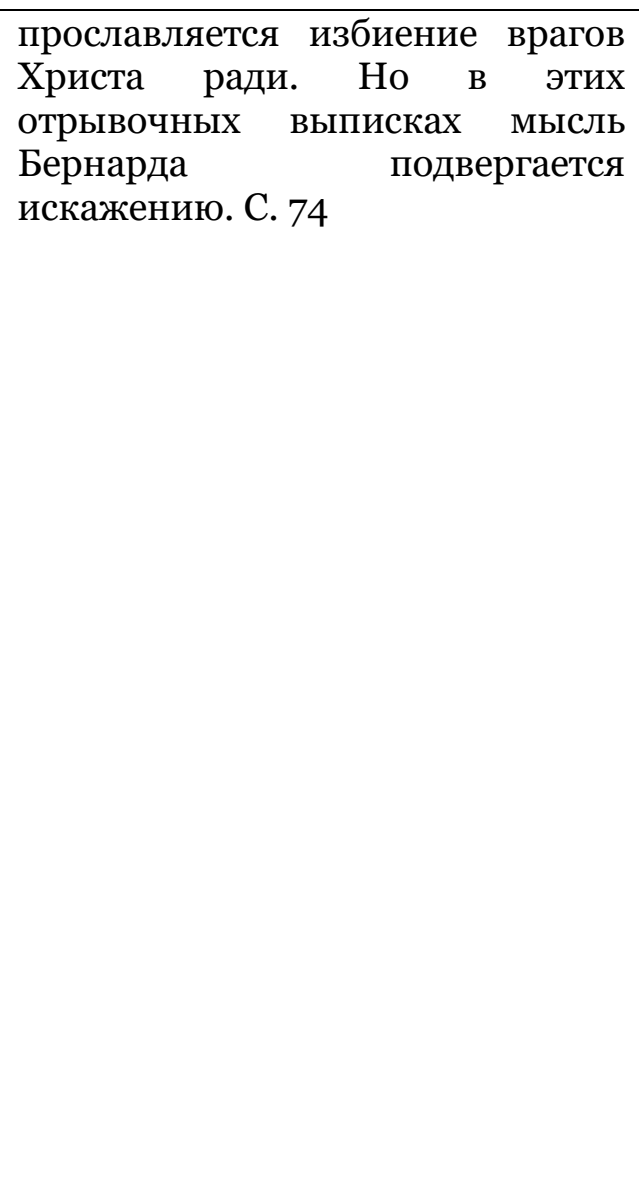 & $\begin{array}{l}\text { loin de craindre la mort, la désirent, et } \\
\text { leur mort sur le champ de bataille est } \\
\text { de toutes les saintes morts la plus } \\
\text { sainte, car ils meurent pour Dieu (2).» } \\
\text { Cependant saint Bernard repousse } \\
\text { toute espèce de guerre, il n'y voit que } \\
\text { des passions condamnables, l'ambition, } \\
\text { la cupidité, la vengeance; le vainqueur } \\
\text { et le vaincu, dit-il, sont également à } \\
\text { plaindre, parce que l'un commet un } \\
\text { péché mortel et que l'autre encourt la } \\
\text { mort de l'âme: à ce point de vue, des } \\
\text { moines faisant profession de verser le } \\
\text { sang n'étaient-ils pas une veritable } \\
\text { monstruosité? «Les chevaliers du } \\
\text { Christ, répond saint Bernard, peuvent } \\
\text { en toute sécurité combattre les } \\
\text { infidèles, car ils combattent pour Dieu } \\
\text { (1). Donner ou recevoir la mort n'est } \\
\text { pas un péché pour eux, c'est une action } \\
\text { des plus glorieuses. Ils sont les } \\
\text { ministers de Dieu pour exercer sa } \\
\text { vengeance; la mort qu'ils donnent est } \\
\text { un profit pour le Christ, le Fils de Dieu } \\
\text { aime de recevoir le sang de ses } \\
\text { ennemis, il est glorifié dans la mort des } \\
\text { païens (2).» }\end{array}$ \\
\hline
\end{tabular}

Вызывает вопрос вторая цитата, представленная в данной таблице. Действительно, на 253 странице седьмого тома «Исследования истории человечества» Лоран рассказывает о феодальных войнах и соперничестве английских и французских королей. На указанной странице мы не находим каких-либо упоминаний святого Бернарда или цитат из его сочинений. У Герье указано, что он использовал второе издание седьмого тома работы Лорана. Нами использовался документ, отсканированный с этого издания, которое хранится в библиотеке Robarts университета Торонто. Однако, если на 253 странице мы ничего не находим, то 289 и 290 страницы как раз содержат то, о чем писал Герье. Неизвестно, с чем связана такая ошибка, но наиболее вероятно, что ее причина - опечатка.

Другое исследование, на которое Герье активно ссылается в своей книге, - это работа англичанина Джеймса Огастуса Коттера Морисона (James Augustus Cotter Morison, 18321888) «Жизнь и времена святого Бернарда» («The Life and Times of St. Bernard»). Это сочинение было опубликовано в Лондоне в 1863 году. Однако, прежде чем мы перейдем к рассмотрению данной книги, следует обратиться к фигуре самого Морисона. С 1834 по 1840 год он жил со своим отцом в Париже, где приобрел не только знание местного языка, но и интерес к истории Франции. В 1850 году он поступил в оксфордский ЛинкольнКолледж (Lincoln College, Oxford) и обучался там до 1859 года. В университете он приобрел множество знакомых, которые повлияли на его взгляды (Stephen, 1894). Морисон был историком-любителем, не стремившимся построить академическую карьеру (Historicism and Human Sciences..., 2017). Морисон стоял на позитивистских позициях, как и многие другие английские интеллектуалы конца XIX века (Historicism and Human Sciences..., 2017).

Книга «Жизнь и времена святого Бернарда» посвящена Томасу Карлайлу (Thomas Carlyle), шотландскому философу, историку и математику, который был одним из главных сторонников и разработчиков теории великих людей. По мнению Карлайла, «мировая история - ни что иное как биография великих людей» (Carlyle, 1841). Карлайл оказал на Морисона значительное влияние, что можно проследить на страницах книги о святом Бернарде последнего. 
«Жизнь и времена святого Бернарда» рассматривает все основные события в жизни Бернарда Клервоского, поднимая при этом темы, так или иначе связанные с ним: учение Пьера Абеляра, Крестовые походы, правление Людовика VI, смерть Карла Доброго и так далее.

Здесь мы приведем ссылки, которые Герье дает на работу Морисона:

\begin{tabular}{|c|c|c|}
\hline $\begin{array}{l}\text { Из приведенного факта, однако, } \\
\text { не следует заключать, чтобы } \\
\text { Бернард был равнодушен к } \\
\text { природе. Напротив, он говорит о } \\
\text { ней в своих сочинениях с таким } \\
\text { чувством, что один из его } \\
\text { последних биографов } \\
\text { приписывает ему даже любовь к } \\
\text { природе 1). С. } 32\end{array}$ & $\begin{array}{l}\text { 1) Morison. Life } \\
\text { and Times of St. } \\
\text { Bernard. 1884, p. } \\
20 .\end{array}$ & $\begin{array}{l}\text { Цитата на указанной странице: } \\
\text { But, even according to his own } \\
\text { showing in after life, there was } \\
\text { another influence to which he owed } \\
\text { more than to all his austerities, and } \\
\text { that was his love of, and communion } \\
\text { with, Nature. His ardent } \\
\text { imagination, which gave a mystic } \\
\text { and manifold meaning to outward } \\
\text { facts, his love for peace and } \\
\text { meditation, his truly Christian and } \\
\text { jubilant heart, which ever gave } \\
\text { thanks for all things, all contributed } \\
\text { to give him this fond delight in } \\
\text { Nature,... }\end{array}$ \\
\hline 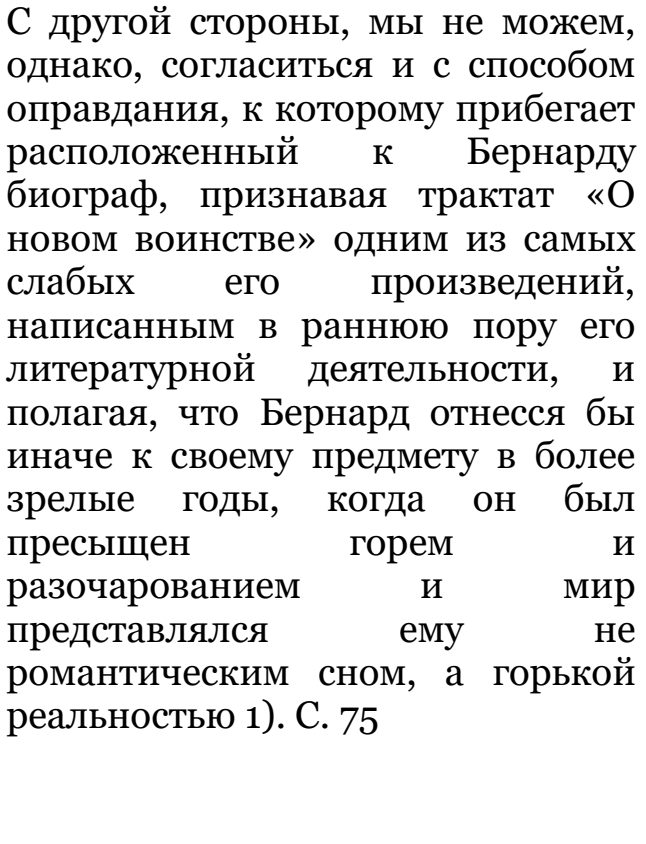 & $\begin{array}{l}\text { 1) Morrison, p. } \\
115 .\end{array}$ & $\begin{array}{l}\text { Цитату находим на 145 странице } \\
\text { указанного сочинения: } \\
\text { On the whole this exhortation must } \\
\text { be set down as one of Bernard's } \\
\text { weakest compositions. It sprang } \\
\text { much more from his rhetorical } \\
\text { imagination than from his deep and } \\
\text { fervent soul. He wrote it in the early } \\
\text { morning of his influence and rising } \\
\text { fame. In after years, when sorrow, } \\
\text { disappointment, and sick- ness had } \\
\text { subdued and saddened him, when } \\
\text { the men and things of this world had } \\
\text { passed from a romantic dream to a } \\
\text { painful reality, it is at least probable } \\
\text { that, if he had written anything at all } \\
\text { on the subject, it would have been in } \\
\text { a different strain. }\end{array}$ \\
\hline $\begin{array}{l}\text { Нарекания на Бернарда слышатся } \\
\text { и теперь, и даже преувеличенные; } \\
\text { разве это «не признание } \\
\text { намеренного двоедушия» со } \\
\text { стороны Бернарда? - восклицает } \\
\text { один из современных нам } \\
\text { историков 1). С. } 106\end{array}$ & $\begin{array}{l}\text { 1) Моррисон } \\
\text { (Life of St. Bern., } \\
\text { 347) } \\
\text { полемизирует } \\
\text { по этому поводу } \\
\text { c Arbois de } \\
\text { Jubainville, } \\
\text { защищающим } \\
\text { Бернарда. } \\
\text { Клерикальный } \\
\text { историк abbe } \\
\text { Ratisbonne } \\
\text { совсем }\end{array}$ & $\begin{array}{l}\text { Цитата взята из сноски на } \\
\text { указанной странице: } \\
\text { It is absurd to argue, as M. D'Arbois } \\
\text { de Jubainville does, that this is not a } \\
\text { confession of intended duplicity on } \\
\text { the part of Bernard and the clerical } \\
\text { party. The terms which the king and } \\
\text { Ralph offered were, that the would } \\
\text { withdraw their forces from } \\
\text { Theobald's territory, if he would } \\
\text { make their peace with the Pope. } \\
\text { Ralph was excommunicated, not as } \\
\text { assailant of Theobald in the field, but }\end{array}$ \\
\hline
\end{tabular}




\begin{tabular}{|l|l|l|}
\hline & $\begin{array}{l}\text { умалчивает } \\
\text { данном факте. }\end{array}$ & $\begin{array}{l}\text { as a sinner, living in adultery with a } \\
\text { concubine. If the crime existed still - } \\
\text { which it did - it was wrong to raise } \\
\text { the interdict; if it had been } \\
\text { condoned, as a condition of peace, } \\
\text { it was wrong to renew it, which was } \\
\text { soon after done, as the weaker party } \\
\text { clearly foresaw. }\end{array}$ \\
\hline
\end{tabular}

Мы сразу можем отметить ошибку, которая допущена в книге Герье: вторая цитата из Морисона обнаруживается не на 115 странице, а на 145. Вероятно, что это можно объяснить простой опечаткой, в пользу чего говорит схожесть написания цифр 1 и 4. Цитаты, которые приводит Герье, представляют собой точный перевод того, что мы находим в тексте самого Морисона. Как мы можем видеть, в приведенных фрагментах различается то, как Герье оценивает работу Морисона. В одном из них он называет Морисона "расположенным к Бернарду биографом», в другом критикует его за «преувеличенные» нарекания на Бернарда. Тем не менее, на наш взгляд, можно отметить, что Герье считал, что Морисон положительно оценивал фигуру Бернарда. Учитывая, что «Жизнь и времена святого Бернарда» посвящена Карлайлу, мы можем с уверенностью предположить, что Морисон полагал Бернарда как раз одним из великих людей, повлиявших на ход истории (Historicism and Human Sciences..., 2017).

Судя по всему, для Герье работы Лорана и Морисона стали чем-то вроде двух полюсов отношения к Бернарду: для одного он был ненавистником научного знания и клерикалом, а для другого - великим умом и представителем Возрождения XII века. Вероятно, сам Герье стремился занять промежуточную позицию, хотя его отношение к истории и роли личности в ней явно приближают его к позиции Морисона.

Еще одна ссылка в сочинении Герье, которая заслуживает нашего внимания - это ссылка на статью Евгения Карелина в журнале «Православное обозрение» за июль-август 1889 года. Важно отметить, что эта сноска не на цитату из статьи Корелина, а руководство для читателя, который в указанной статье сможет найти упомянутые Герье проповеди:

\begin{tabular}{|l|l|l|}
\hline Еще большую известность получили проповеди & 1) См. Евг. Корелин: Бернард \\
1), произносившиеся Бернардом перед & Клервосский, церковный деятель и \\
монахами его монастыря, и которыми & $\begin{array}{l}\text { проповедник. Православ. Обзор. 1889, } \\
\text { интересовались и вне монастыря. С. } 48\end{array}$ & \multicolumn{2}{l}{ июль-авг. } \\
\hline
\end{tabular}

Корелин в своей статье излагает содержание 340 речей и проповедей, которые в конце XIX века считались подлинными сочинениями Бернарда (Никитин, 2010). Эта сноска довольно редкий пример ссылки на работу другого отечественного специалиста.

\section{4. Результаты}

На основании анализа справочного аппарата, мы можем отметить, что при написании своей работы Герье больше всего использовал исследования Лорана и Морисона. Вместе с тем, его книга полемизирует с этими авторами, а подавляющее большинство сносок в ней это ссылки на тексты самого Бернарда Клервоского, изданные Минем или Вакандардом. Отношение Герье к герою его сочинения и оценка его деятельности не испытали сильного влияния работ Лорана и Морисона, они формировались в процессе изучения наследия самого Бернарда.

\section{5. Заключение}

Насколько мы можем судить по его работе, Герье была близка идея восприятия истории как биографии «великих людей». Эта идея была особенно популярна в начале XIX века, в эпоху романтизма. Так как Герье в своем сочинении опирается на труд Джеймса Морисона, мы можем отметить его связь с трудами Томаса Карлайла, одного из главных разработчиков теории «великих людей». Карлайл, в свою очередь, испытал значительное 
влияние немецкого романтизма, так что в поисках истока такого восприятия истории мы можем обратиться к немецкой традиции.

Так, благодаря анализу справочного аппарата, мы можем проследить сразу несколько линий, которые связывают Герье с различными историографическими традициями. Именно через ссылки мы смогли увидеть, как сам Герье оценивал те сочинения, которыми он пользовался, что помогает нам сделать выводы относительно влияния на него того или иного сочинения.

\section{Литература}

Вайнштейн, 1940 - Вайнштейн О.Л. Историография Средних веков. М.: 1940. С. 307.

Герье, 1913 - Герье В.И. Западное монашество и папство. М.: 1913.

Никитин, 2010 - Никитин А. Изучение личности и творчества Бернарда Клервоского (1091-1153) в русской науке. Христианское чтение, 2010, 1.

Arnold of Brescia, 1917 - Arnold of Brescia. Vacandard. The Catholic encyclopedia and its makers. New York, 1917.

Bredero Adriaan, 1996 - Bredero Adriaan H. Bernard of Clairvaux. Between Cult and History. Edinburgh, 1996.

Carlyle, 1841 - Carlyle T. On Heroes, Hero-worship, \& the Heroic in History. London: James Fraser, 1841.

Historicism and the Human Sciences..., 2017 - Historicism and the Human Sciences in Victorian Britain. Cambridge, 2017.

Lameere, 1905 - Lameere J. Notice sur François Laurent. Annuaire. Bruxelles: Académie royale des sciences, des lettres et des beaux-arts de Belgique, 1905.

Stephen, 1894 - Stephen L. Morison, James Augustus Cotter. Dictionary of National Biography, 1885-1900. Vol. 39. 1894.

\section{References}

Ger'e, 1913 - Ger'e V.I. (1913). Zapadnoe monashestvo i papstvo [Western monasticism and the papacy]. M.

Nikitin, 2010 - Nikitin A. (2010). Izuchenie lichnosti i tvorchestva Bernarda Klervoskogo (1091-1153) v russkoi nauke [The study of the personality and creativity of Bernard Clairworthy (1091-1153) in Russian science]. Khristianskoe chtenie, 1.

Vainshtein, 1940 - Vainshtein O.L. (1940). Istoriografiya Srednikh vekov [Historiography of the Middle Ages]. M., P. 307.

Arnold of Brescia, 1917 - Arnold of Brescia. Vacandard. The Catholic encyclopedia and its makers. New York, 1917.

Bredero Adriaan, 1996 - Bredero Adriaan H. Bernard of Clairvaux. Between Cult and History. Edinburgh, 1996.

Carlyle, 1841 - Carlyle T. On Heroes, Hero-worship, \& the Heroic in History. London: James Fraser, 1841.

Historicism and the Human Sciences..., 2017 - Historicism and the Human Sciences in Victorian Britain. Cambridge, 2017.

Lameere, 1905 - Lameere J. Notice sur François Laurent. Annuaire. Bruxelles: Académie royale des sciences, des lettres et des beaux-arts de Belgique, 1905.

Stephen, 1894 - Stephen L. Morison, James Augustus Cotter. Dictionary of National Biography, 1885-1900. Vol. 39. 1894. 
Научные связи в работах В. И. Герье (1837-1919). Анализ справочного аппарата

Константин Антонович Миненко ${ }^{\text {a, * }}$

a Санкт-Петербургский государственный университет, Российская Федерация

Аннотация. В данной статье анализ справочного аппарата будет использован для выявления научных связей. Нами будет проанализирована работа известного российского историка Владимира Ивановича Герье «Западное монашество и папство», часть которой посвящена жизни и произведениям Бернарда Клервоского. Анализируя справочный аппарат в этой работе, мы выясним, какие именно авторы оказали на Герье наибольшее влияние при написании «Западного монашества и папства». Мы также изучим непосредственно самих этих авторов, их методологию и научный бэкграунд. Это позволит нам продемонстрировать, как традиция восприятия истории как биографии великих людей повлияла на российскую историографическую традицию.

Ключевые слова: история науки, Герье, медиевистика, справочный аппарат, методология.

${ }^{*}$ Корреспондирующий автор

Адреса электронной почты: koxminenko@gmail.com (К.А. Миненко) 